\title{
Trends in rainfall and rainfall-related extremes in the east coast of peninsular Malaysia
}

\author{
Olaniya Olusegun Mayowa, Sahar Hadi Pour, Shamsuddin Shahid, \\ Morteza Mohsenipour* (D, Sobri Bin Harun, Arien Heryansyah \\ and TARMIZI ISMAIL \\ Department of Hydraulics and Hydrology, Faculty of Civil Engineering, Universiti Teknologi Malaysia (UTM), \\ 81310 JohorBahru, Malaysia. \\ *Corresponding author.e-mail: mmorteza2@live.utm.my
}

The coastlines have been identified as the most vulnerable regions with respect to hydrological hazards as a result of climate change and variability. The east of peninsular Malaysia is not an exception for this, considering the evidence of heavy rainfall resulting in floods as an annual phenomenon and also water scarcity due to long dry spells in the region. This study examines recent trends in rainfall and rainfallrelated extremes such as, maximum daily rainfall, number of rainy days, average rainfall intensity, heavy rainfall days, extreme rainfall days, and precipitation concentration index in the east coast of peninsular Malaysia. Recent 40 years (1971-2010) rainfall records from 54 stations along the east coast of peninsular Malaysia have been analyzed using the non-parametric Mann-Kendall test and the Sen's slope method. The Monte Carlo simulation technique has been used to determine the field significance of the regional trends. The results showed that there was a substantial increase in the annual rainfall as well as the rainfall during the monsoon period. Also, there was an increase in the number of heavy rainfall days during the past four decades.

\section{Introduction}

Climate is a dynamic phenomenon, which changes over time and space. Climate in southeast Asia is changing due to global warming both on global and regional scales (Manton et al. 2001; Deni et al. 2009; Suhaila and Jemain 2009; Zawiah et al. 2010; Ercan et al. 2012; Hassan et al. 2013; Lacombe et al. 2013; Lin et al. 2013; Pour et al. 2014). Climate change is likely to cause sharp increases in temperature, which in turn is likely to affect evapotranspiration and atmospheric water storage, thereby potentially changing the magnitudes, frequencies and intensities of rainfall as well as its seasonal and inter-annual variabilities and geographical distributions (Wang et al. 2014). Therefore, future climate changes may involve modifications in climatic variability as well as changes in averages (Shahid 2011). The implications of these changes are particularly significant for areas that are already under stress such as the coastal regions of southeast Asia, which is very sensitive to rainfall characteristics due to its geographical position in the equatorial belt and prominent diurnal variability in rainfall in addition to the topographical interactions (Oki and Musiake 1994; Chang and Kwon 2007). Small changes in the mean and variance due to climate change can produce relatively large changes in the probability of extreme events ( $\mathrm{Su}$ et al. 2006). As the primary impacts of climate change on society results from extreme events (Rodrigo 2002), it might have severe negative consequences in already stressed

Keywords. Climate variability; rainfall trends; rainfall indices; coastline; hydrological hazards. 
coastal regions. Therefore, an understanding of the ongoing changes in climate and climate-related extremes is of central importance for adopting adaptation measures to mitigate negative impacts of climate change (Tangang et al. 2012).

Though Malaysia is considered to be one of the less prone regions to natural disasters, it is anticipated that increasing trends in climate-related extremes may make the country more vulnerable to climate change and natural disasters (Wong et al. 2009; Toriman et al. 2009; Deni et al. 2010; Suhaila et al. 2010). The geographic distribution of climate change vulnerability is not uniform over the entire country, i.e., the east coast of peninsular Malaysia is more vulnerable to climate change than the west (Yusuf and Francisco 2009). Floods triggered by heavy rainfall has become almost an every year phenomena in the east coast states of peninsular Malaysia (Lim and Samah 2004; MMD 2009). Water scarcity due to prolonged dry spells is also felt in the upper part of east coast region. It has been projected that annual rainfall in the east coast of Malaysia will be more variable by the end of this century (NAHRIM 2006). It is anticipated that variability in inter-annual and interseasonal rainfall due to climate change will cause more hydrologic extremes in the east coast of peninsular Malaysia and make the livelihood and infrastructure more vulnerable.

A number of recent studies have addressed historical change in the climate and climate-related extremes in Malaysia (Wong et al. 2009; Toriman et al. 2009; Deni et al. 2010; Suhaila et al. 2010). All these studies analysed rainfall-related extremes based on only a few stations to infer the changes in climate. However, no study has been carried out so far focusing east coast of peninsular Malaysia which is the most vulnerable climate change zone in Malaysia.

In the present study, recent 40 years (1971-2010) rainfall data collected from 54 stations located along the east coast of Malaysia has been analyzed using non-parametric statistical methods to determine the recent trends in rainfall, and various rainfall-related extremes such as rainfall intensity, total wet days, monsoon rainfall consecutive dry days, low rainfall days, consecutive wet days, cumulative 5-day precipitation total, maximum 1day rainfall, maximum 5-day rainfall, high rainfall day, extreme rainfall day and precipitation concentration index (PCI). Mann-Kendall test (Mann 1945; Kendall 1975) is used to detect the trend and the Sen's slope method (Sen 1968) is used to determine the magnitude of change in rainfall time series. The Monte Carlo simulation technique is used to determine the significance of the regional trend pattern (Serra et al. 2006). A complete analysis of climate events requires analysis of both their spatial and temporal extent (Shahid and Khairulmaini 2009; Shahid 2010a). Climatic investigation over a large area requires assimilation of information from many sites each with a unique geographic location. Geographical Information System (GIS) maintains the spatial location of sampling points, and provides tools to relate the sampling data contained through a relational database (Shahid et al. 2000). In the present paper, GIS is used to analyze the spatial variation in the trends of rainfall and rainfall-related extremes. Implications from this study will help to understand possible changes in rainfall in order to take policy measures to adapt with the changing pattern of climate in the region.

\section{Materials and methods}

\subsection{Climate of the east coast of peninsular Malaysia}

The map of the study area in peninsular Malaysia, encompassing the region $1^{\circ}-7^{\circ} \mathrm{N}$ and $100^{\circ}-103^{\circ} \mathrm{E}$, is shown in figure 1 . The east coast of peninsular Malaysia has a tropical climate characterized by uniform high temperature, high humidity and copious rainfall. The climate of the area can be loosely divided into four seasons:

- the north-east monsoon from December to March,

- a transitional period from April to May,

- the south-west monsoon from June to September, and

- a transitional period from October to November. Heaviest rain spells are usually observed during the northeast monsoon season (Pour et al. 2014).

On the other hand, months of June and July during southwest monsoon are the driest period. Substantial rainfall also occurs in the transitional periods that usually occur in April and October, between the monsoon seasons (Suhaila and Jemain 2007). The east coast of peninsular Malaysia has uniform temperature throughout the year. The annual variation is less than $2^{\circ} \mathrm{C}$ around the mean temperature of $27^{\circ} \mathrm{C}$ (Suhaila et al. 2008).

\subsection{Data and methodology}

Forty-year (1971-2010) daily rainfall records from 54 stations, collected from the Department of Irrigation and Drainage (DID) of Malaysia, are used in this study. The locations of these stations are shown in figure 2. It is often a major problem to work rainfall records of Malaysia due to missing data. Therefore, out of more than hundred rainfall stations, data from only 54 stations that have fewer 


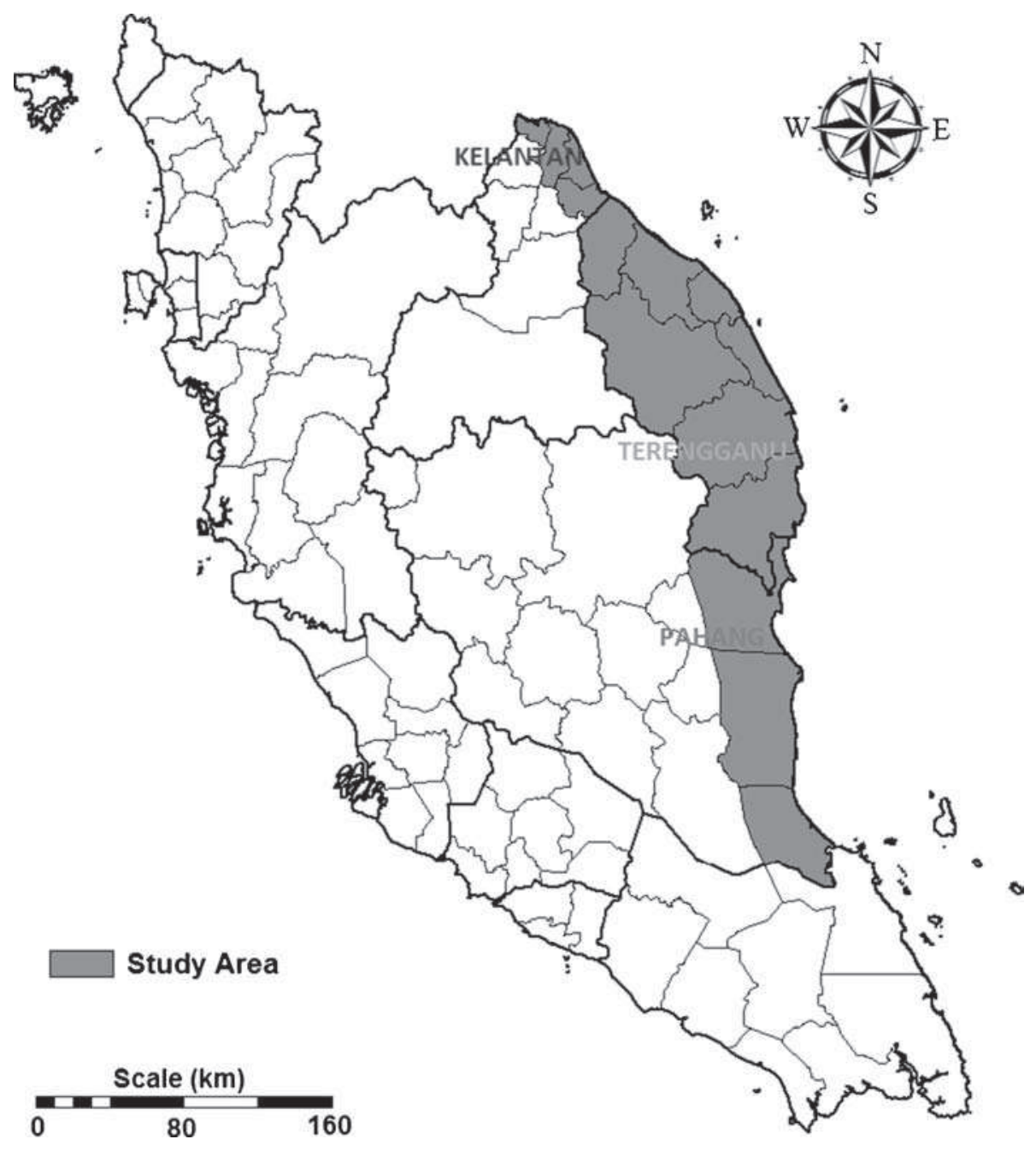

Figure 1. Location of the study area in the map of peninsular Malaysia.

amounts of missing data are used in the present study. Amount of missing data in the stations under study is found to be less than $2 \%$ in all stations. If more than three missing data is found in a month, the data of that year is discarded for analysis. Otherwise, missing data are filled with rainfall of nearest stations using expectation maximization (EM) algorithm (Dempster et al. 1977; Alamgir et al. 2015).

Data quality control is a necessary step before the calculation of indices because erroneous outliers can seriously impact the indices calculation and their trends (You et al. 2008; Shahid et al. 2015). A number of data checks is carried out to ensure the quality control of datasets such as negative precipitation values, more than 30 consecutive dry days during monsoon, etc. Histograms are generated to see if there are problems associated with the dataset. This histogram analysis showed that there is no apparent problem associated with data from any station used in this study.

To detect the inhomogenities in the data series, both subjective double mass curve method and the objective Student t-test are applied. The cumulative rainfall of a station is plotted against the average cumulative rainfall of 54 stations over the area to show the double mass curve. The double mass curves of all stations display almost a straight line which represents the data homogeneity. Running Student's t-test is also used to test the difference in the means between two segments of a data set to insure homogeneity in data. It has been found that differences between the subset series are not significant at $95 \%$ level of confidence at any station. Therefore, it is clear that there is no statistically significant variation or break point existing in the rainfall time series in any of the 54 stations. A total of eleven rainfall-related extreme indices are computed. Description of the indices is given in table 1. Some indices are based on threshold defined as percentiles. The percentiles are calculated from the reference period 1971-2000.

In the present study, the non-parametric MannKendall trend test (Mann 1945; Kendall 1975) is used to analyze the trends of rainfall and rainfall extremes. The Mann-Kendall test has proven to 
be useful in determining the possible existence of statistically significant trends at different probability levels (Shahid 2010a). In the present study,

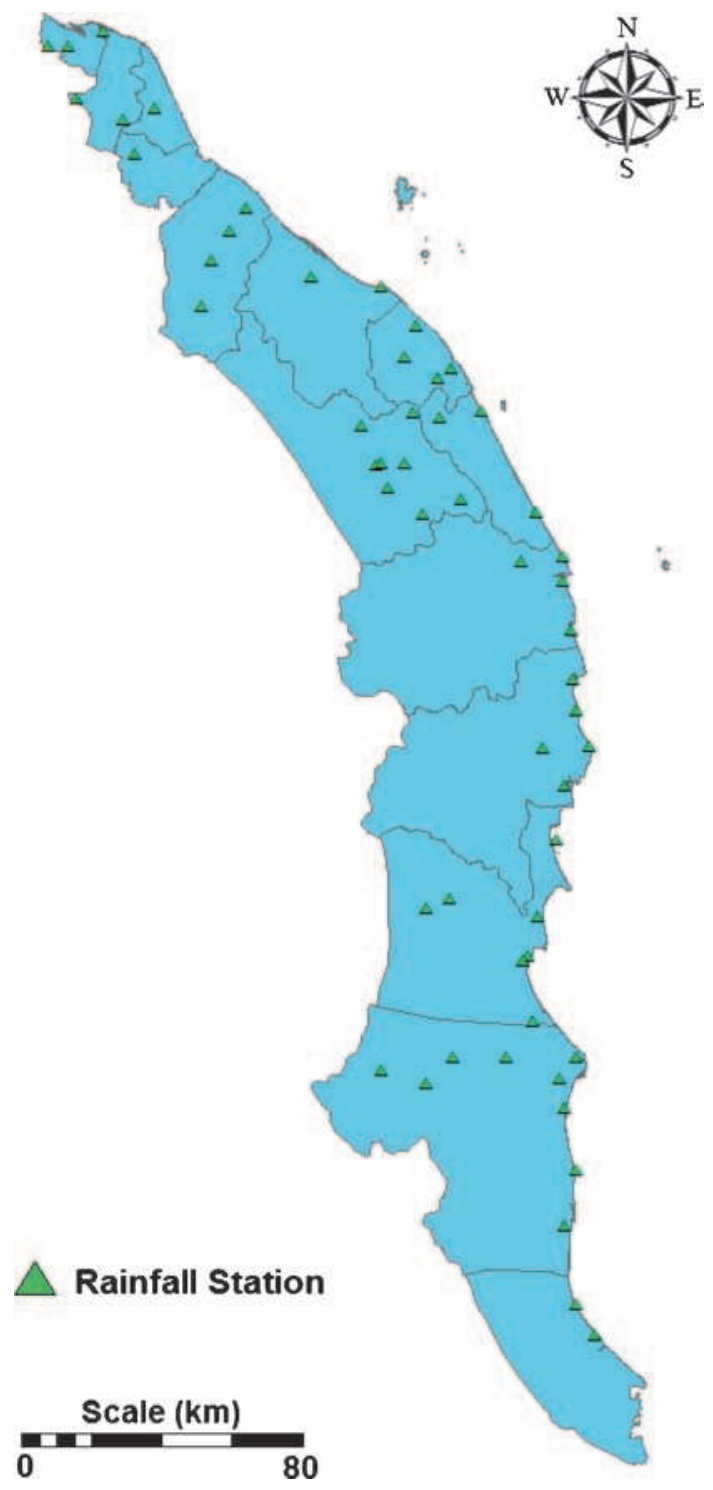

Figure 2. Location of rainfall stations in the east coast of peninsular Malaysia. confidence levels of $90 \%, 95 \%$, and $99 \%$ are taken as thresholds to classify the significance of positive and negative trends. The Sen's slope method (Sen 1968) is used to estimate the magnitude of change of the events. The Monte Carlo simulation technique is used to determine the significance of the regional trend pattern (Serra et al. 2006). The methods used in the present study are discussed below.

\subsubsection{Mann-Kendall trend test}

In Mann-Kendall test (Mann 1945; Kendall 1975), the data is evaluated as an ordered time series. Each data point is compared against all its subsequent points. The initial value of the MannKendall statistic, $S$, is assumed to be zero (e.g., no trend). $S$ is incremented (decremented) by 1 , if the data from a later (earlier) time period is larger than from an earlier (later) time period. The net result of all such increments and decrements yields the final value of $S$. If $x_{1}, x_{2}, x_{3}, \ldots, x_{i}$ represent $n$ data points where $x_{j}$ represents the data point at time $j$, then $S$ is given by:

$$
S=\sum_{k=1}^{n-1} \sum_{j=k+1}^{n} \operatorname{sign}\left(x_{j}-x_{k}\right),
$$

where

$$
\operatorname{sign}\left(x_{j}-x_{k}\right)=\left\{\begin{aligned}
1 & \text { if }\left(x_{j}-x_{k}\right)>0 \\
0 & \text { if }\left(x_{j}-x_{k}\right)=0 . \\
-1 & \text { if }\left(x_{j}-x_{k}\right)<0
\end{aligned}\right.
$$

The probability associated with $S$ and the sample size, $n$, are then computed to statistically quantify the significance of the trend. Normalized test statistic $Z$ is computed as follows:

$$
Z=\left\{\begin{array}{cl}
\frac{S-1}{\sqrt{\operatorname{VAR}(S)}} & \text { if } S>0 \\
0 & \text { if } S=0 \\
\frac{S-1}{\sqrt{\operatorname{VAR}(S)}} & \text { if } S<0
\end{array}\right.
$$

\begin{tabular}{|c|c|c|}
\hline Index & Descriptive name & Unit \\
\hline $\mathrm{RI}$ & Average rainfall on wet days in a year & $\mathrm{mm} /$ day \\
\hline TWD & Total number of rainy days (rainfall $>0$ ) in a year & day \\
\hline CDD & Maximum number of consecutive dry days (rainfall $=0$ ) in a year & day \\
\hline $\mathrm{CDR}<1$ & Maximum number of consecutive low rainfall days (rainfall $\leq 1$ ) in a year & day \\
\hline CWD & Maximum number of consecutive wet days (rainfall $>0$ ) in a year & day \\
\hline C5DPT & Cumulative 5-day precipitation total & $\mathrm{mm}$ \\
\hline Max1DR & Maximum 1-day rainfall amount in a year & $\mathrm{mm}$ \\
\hline M5DR & Maximum 5-day rainfall amount in a year & $\mathrm{mm}$ \\
\hline Rain $>20 \mathrm{~mm}$ & Total number of days in a year with rainfall $>20 \mathrm{~mm}$ & day \\
\hline Rain $>95$ pctl & Annual total rainfall when rainfall $>$ 95th percentile of $1971-2010$ daily rainfall & day \\
\hline PCI & Precipitation concentration index & $\%$ \\
\hline
\end{tabular}

Table 1. Definition of precipitation indices used in the study. 
At $99 \%$ significance level, the null hypothesis of no trend is rejected if $|Z|>2.575$; at $95 \%$ significance level, the null hypothesis of no trend is rejected if $|Z|>1.96$; and at $95 \%$ significance level, the null hypothesis of no trend is rejected if $|Z|>1.645$. More details of Mann-Kendall test can be found in Sneyers (1990).

\subsubsection{Sen's slope estimator}

Some trends may not be evaluated to be statistically significant, while they might be of practical interest (Yue and Hashino 2003; Basistha et al.
2007). Even if climate change component is present, it may not be detected by statistical tests at a satisfactory significance level (Radziejewski and Kundzewicz 2004). Therefore, a linear trend analysis is also carried out and the magnitude of trend is estimated by Sen's slope method (Sen 1968). Sen's slope method gives a robust estimation of trend (Yue et al. 2002). The method requires a time series of equally spaced data. The method proceeds by calculating the slope as a change in measurement per change in time,

$$
Q^{\prime}=\frac{x_{t^{\prime}}-x_{t}}{t^{\prime}-t}
$$

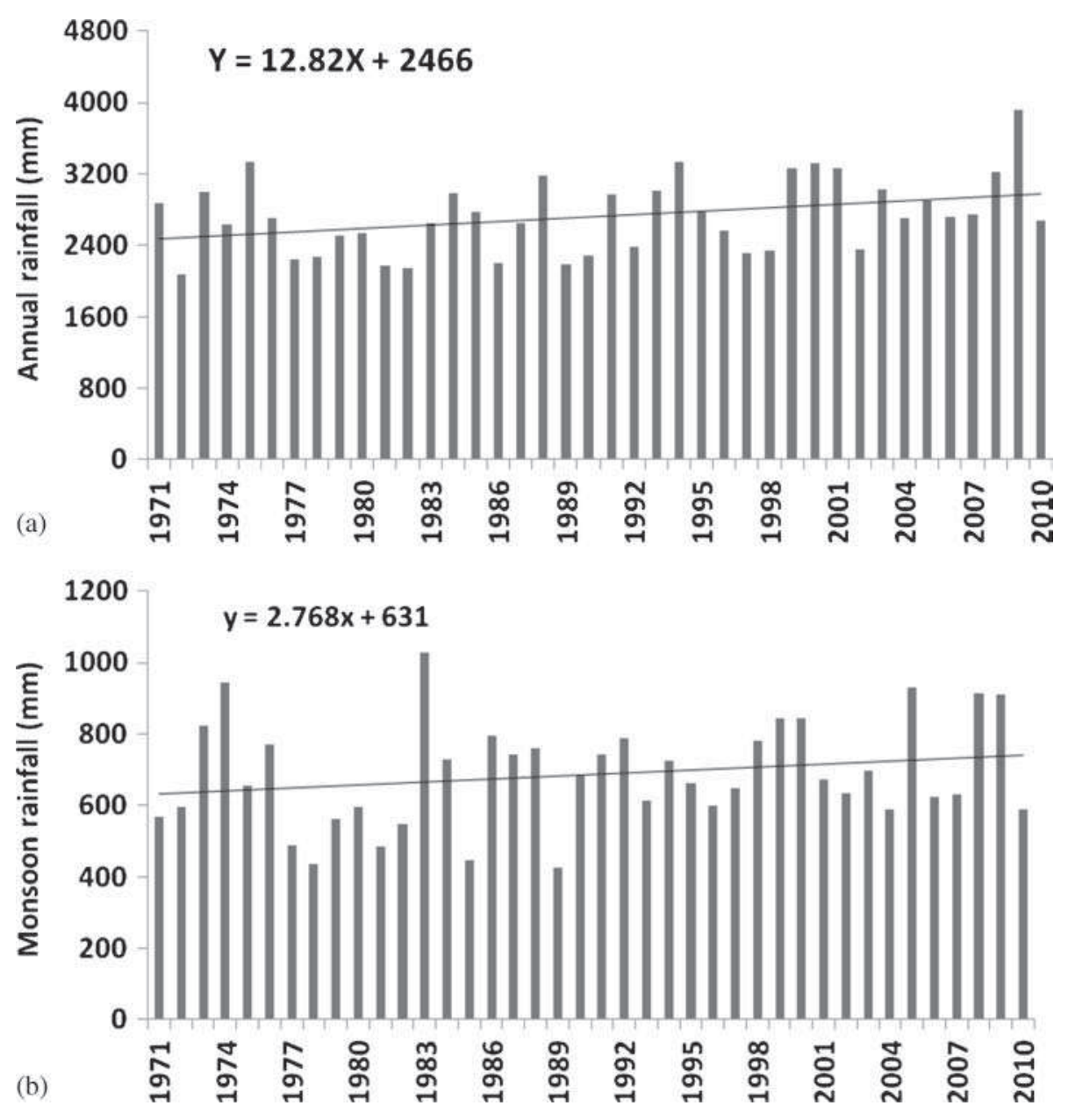

Figure 3. The time series of average (a) annual and (b) NE monsoon rainfalls in the study area for the period 1971-2010.

Table 2. Trends in annual and monsoon rainfalls in the east coast of peninsular Malaysia.

\begin{tabular}{lcccccc}
\hline & & \multicolumn{3}{c}{$\begin{array}{c}\text { Stations with } \\
\text { significant trends }\end{array}$} & & \multicolumn{2}{c}{$\begin{array}{c}\text { Stations with } \\
\text { nainfall }\end{array}$} & $\begin{array}{c}\text { Average } \\
\text { significant trends }\end{array}$ \\
\cline { 3 - 6 } & trend & $\mathrm{p}=0.01$ & $\mathrm{p}=0.05$ & $\mathrm{p}=0.1$ & Increasing \\
\hline Annual & $12.82^{*}$ & - & 8 & 43 & 3 & Decreasing \\
NE monsoon & $2.76+$ & - & 3 & 5 & 44 & 2 \\
\hline
\end{tabular}

${ }^{*} \mathrm{p}=0.05 ;+\mathrm{p}=0.1$. 
where $Q^{\prime}$ is the slope between data points $x_{t^{\prime}}$ and $x_{t}$, $x_{t^{\prime}}$ is the data measurement at time $t^{\prime}$ and $x_{t}$ is the data measurement at time $t$.

Sen's estimator of slope is simply given by the median slope,

$$
Q= \begin{cases}Q_{[(N+1) / 2]}^{\prime} & \text { if } N \text { is odd } \\ \left(Q_{[N / 2]}^{\prime}+Q_{[(N+2) / 2]}^{\prime}\right) / 2 & \text { if } N \text { is even }\end{cases}
$$

where $N$ is the number of calculated slopes.

\subsubsection{Monte Carlo simulation for field significance}

Monte Carlo simulation allows an assessment of whether trends have occurred by chance and it

(a)

\section{Trend in annual rainfall \\ Increasing, not significant \\ Increasing, at $\mathbf{p}=0.1$ \\ Increasing, at $\mathrm{p}=0.05$}
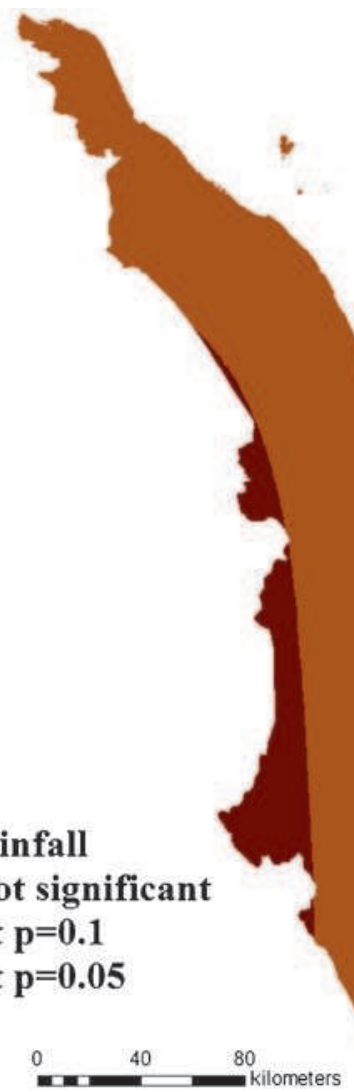

is especially appropriate when spatial correlation between time series exists. Monte Carlo simulations have been used widely to detect field significant trends (Chu and Wang 1997; Zhang et al. 2004; Serra et al. 2006; Shahid et al. 2012).

Time series of rainfall and rainfall-related extremes at each station are concurrently shuffled using a random number generator and linear regression slope is estimated at each station. The total number of stations showing significance at the $90 \%$ confidence level is counted and denoted as $N_{m c}^{i}$, where the superscript $i$ denotes the $i$ th trial and the subscript $m c$ denotes the Monte Carlo experiments. The procedure is repeated thousand times. The field is considered to be significant at

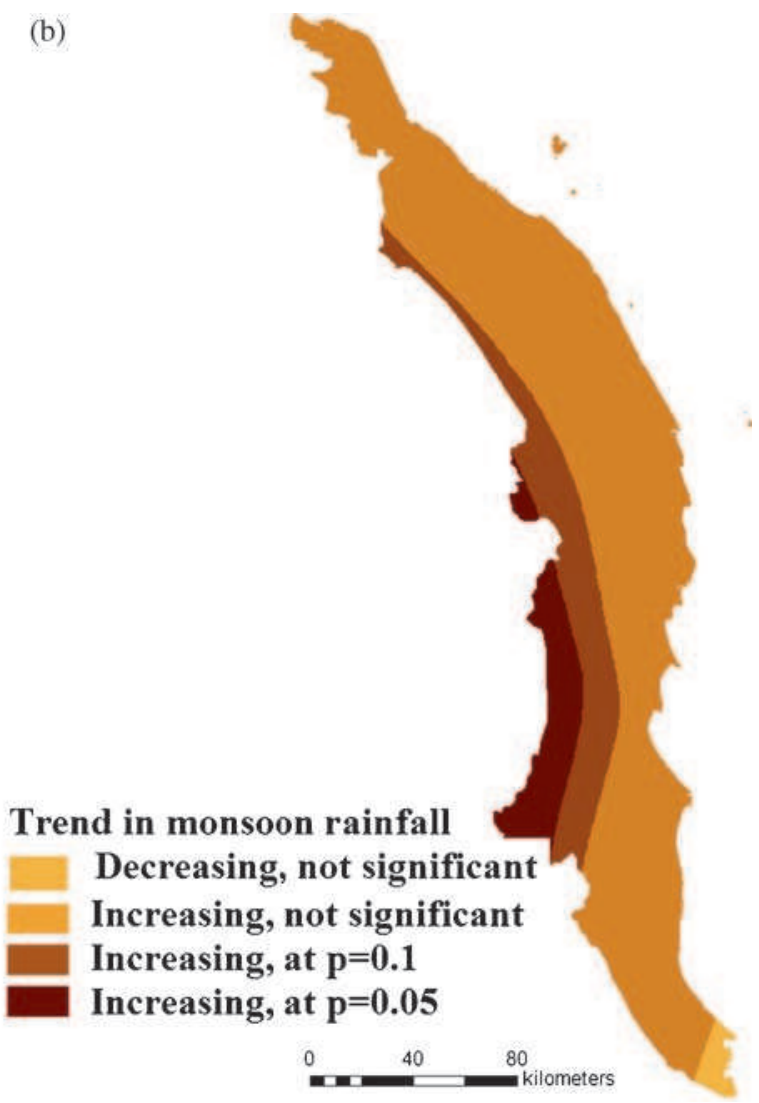

Figure 4. Spatial pattern in average (a) annual rainfall and (b) NE monsoon rainfall.

Table 3. Trends in extreme rainfall events in the east coast of peninsular Malaysia.

\begin{tabular}{|c|c|c|c|c|c|c|}
\hline \multirow[b]{2}{*}{ Index } & \multirow{2}{*}{$\begin{array}{c}\text { Average } \\
\text { trend }\end{array}$} & \multicolumn{3}{|c|}{$\begin{array}{l}\text { Stations with } \\
\text { significant trends }\end{array}$} & \multicolumn{2}{|c|}{$\begin{array}{c}\text { Stations with } \\
\text { no significant trends }\end{array}$} \\
\hline & & $\mathrm{p}=0.01$ & $\mathrm{p}=0.05$ & $\mathrm{p}=0.1$ & Increasing & Decreasing \\
\hline RI & 0.023 & - & 4 & 8 & 28 & 14 \\
\hline TWD & $0.403+$ & - & 16 & 6 & 25 & 7 \\
\hline CDD & -0.26 & - & 3 & 2 & 12 & 37 \\
\hline $\mathrm{CDR}<1$ & -0.28 & - & - & 3 & 10 & 41 \\
\hline CWD & -0.05 & - & - & - & 28 & 26 \\
\hline Rain $>20 \mathrm{~mm}$ & $0.15+$ & - & 4 & 2 & 47 & 1 \\
\hline Rain $>95$ pctl & $0.095+$ & - & 8 & 12 & 24 & 10 \\
\hline
\end{tabular}

$* \mathrm{p}=0.05 ;+\mathrm{p}=0.1$. 
the $90 \%$ level when $N$ exceeds $N_{m c}^{*}$, where $N_{m c}^{*}$ is the 90th percentile of a locally significant trend from 1000 trials.

\subsubsection{Spatial interpolation}

For the mapping of spatial pattern of trends from point data Kriging interpolation method is used. Geostatistical analysis tool of ArcMap10.1 is used for this purpose. Kriging is a stochastic interpolation method (Isaaks and Srivastava 1989), which is widely recognized as the standard approach for surface interpolation based on scalar measurements at different points. Studies show that Kriging gives better global predictions than other methods (van Beers and Kleijnen 2004; Ahmed et al. 2014). Kriging is an optimal surface interpolation method based on spatially dependent variance, which is generally expressed as semi-variogram. Surface interpolation using kriging depends on the selected semi-variogram model and the semi-variogram must be fitted with a mathematical function or model. Depending on the shape of semi-variograms, different models are used in the present study for their fitting.

\section{Results}

For the analysis of trends of rainfall and rainfallrelated extremes in the east coast of peninsular Malaysia, the regional trends over the whole area is carried out. Furthermore, the trends in the rainfall and rainfall-related extremes are calculated at each station and used to prepare the corresponding maps to show the distribution of trends. Details of the results are given below.

\subsection{Trends in rainfall}

Annual and northeast monsoon rainfall recorded at different stations is averaged to show the changes of annual and monsoon rainfall over the study area. A graph of average annual and monsoon rainfall in the study area over the time period 19712010 is shown in figure 3(a and b), respectively. Field significance of the regional trends in annual and monsoon rainfall in the study area estimated using the Monte Carlo method are given in table 2 . The numbers in the table denote the magnitude to change obtained using the Sen's slope method. The significance of change is marked by the symbol besides the number.

It can be seen from table 2 and figure 3 that annual rainfall in the study area has increased at a rate of $12.8 \mathrm{~mm} /$ year in last 40 years. The increase is significant at $95 \%$ level of confidence. The NE monsoon rainfall in the study area is found to have increased at a rate of $2.7 \mathrm{~mm}$ per year. The increase is found to be significant at $90 \%$ level of confidence.

Trends in annual and monsoon rainfall at each station are also shown in table 2. Results showed that annual rainfall has changed significantly at 51 or $94 \%$ stations. The increase is not significant only at 3 stations out of total 54 stations. Monsoon rainfall is found to increase significantly (not significantly) at 8 (44) stations.

Trends at each station are interpolated to map the spatial pattern of rainfall. Figure $4(\mathrm{a}$ and $\mathrm{b})$ shows the spatial pattern of annual and monsoon rainfall trends in the study area, respectively. It can be seen from figure 4(a) that annual rainfall is increasing significantly at $90 \%$ level of confidence along the coast line, while it is increasing at $95 \%$ level of confidence over the inland areas of the east coast of peninsular Malaysia. Figure 4(b) shows that there is no significant change in monsoon rainfall. It is found that monsoon rainfall has increased significantly only in the inner part of the coastal zone.

\subsection{Trends in extreme rainfall events}

Field significance of regional trends in extreme rainfall indices in the study area are given in

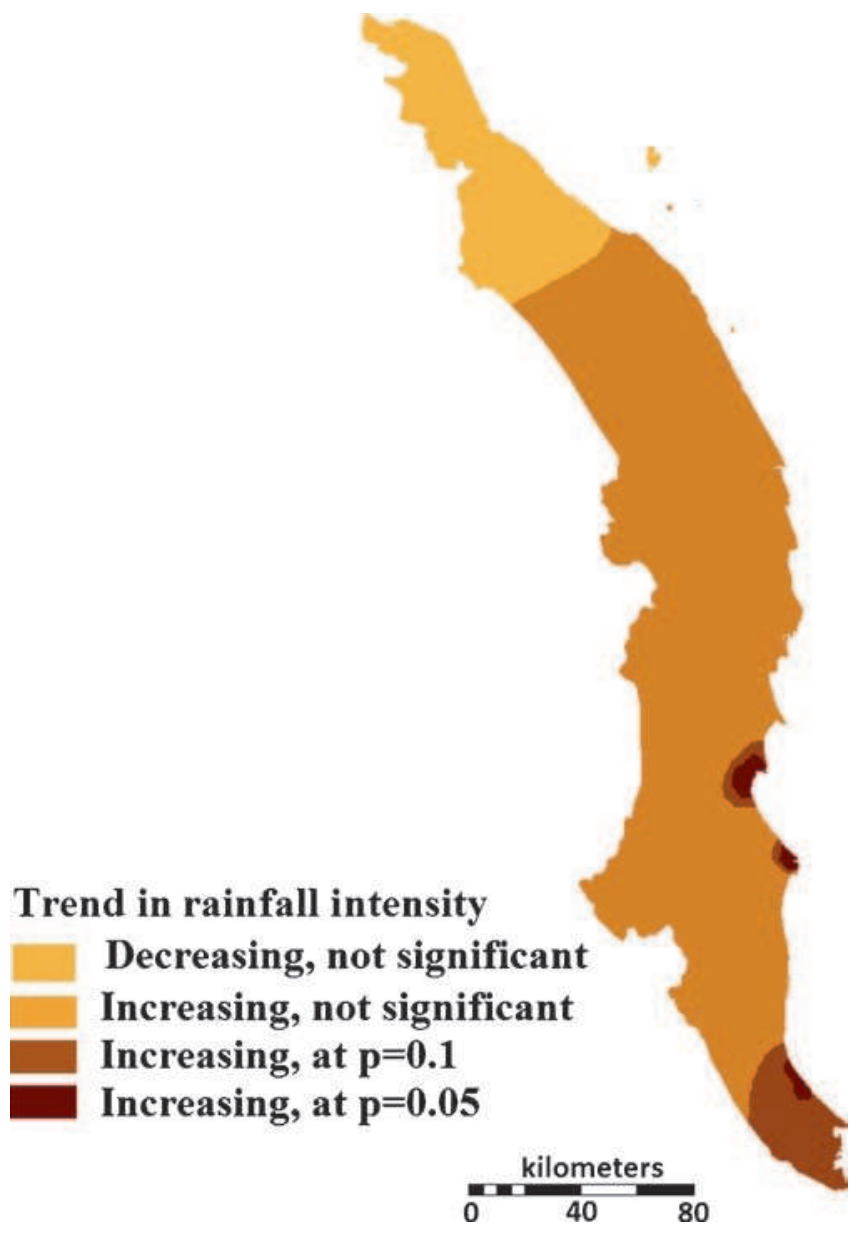

Figure 5. Spatial pattern in rainfall intensity. 
table 3. Trends in extreme rainfall indices are also calculated at each station and interpolated to map the spatial distribution of trends in rainfall extremes. Trends in extreme rainfall indices in the east coast of peninsular Malaysia are discussed below in detail.

\subsubsection{Rainfall intensity}

Regional trend in average rainfall intensity is found non-significant (table 3) in the study area. Out of 54 stations, rainfall intensity is found to increase only at 12 stations. Spatial pattern in the trends of rainfall intensity is shown in figure 5 . Result shows that rainfall intensity has increased significantly only in the lower part of the study area. However, overall there is no significant change in average rainfall intensity in the study area.

\subsubsection{Wet days}

Total number of wet days in a year recorded at different stations is averaged to show the changes of total wet days in the study. The graph of average total wet days over the study area for the period 1971-2010 is shown in figure 6. The figure shows that the total number of wet days in the study area has increased at a rate of approximately

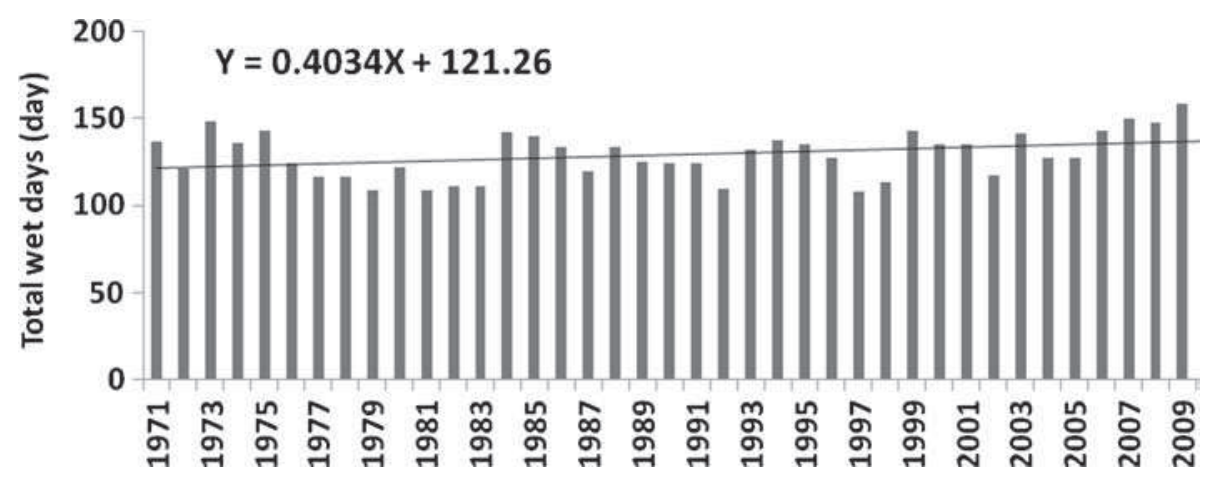

Figure 6. The time series (1971-2010) of annual total wet days in the study area.

(a)

\section{Trend in total wet days}

Decreasing, not significant Increasing, not significant Increasing, at $\mathbf{p}=\mathbf{0 . 1}$ Increasing, at $\mathbf{p}=\mathbf{0 . 0 5}$

$$
=\frac{\text { kilometers }}{40} 80
$$

(b)

\section{Trend in consencutive wet days} Decreasing, not significant Increasing, not significant

$$
0 . \frac{\text { kilometers }}{40}=
$$

Figure 7. Spatial pattern in (a) total wet days and (b) consecutive wet days in the study area. 
4 days/decade in the last 40 years. Field significance of regional trend in wet days showed that it has increased significantly at $90 \%$ level of confidence in the study area (table 3). Out of 54 stations, the number of wet days in a year is found to increase significantly at 22 or $40 \%$ of the stations. Spatial pattern in number of wet days is shown in figure 7 (a). The figure shows that number of wet days has increased significantly only in the upper part of the east coast of peninsular Malaysia.

Field significance of the regional trend in consecutive wet days in the study area (table 3 ) reveal no significant change in number of consecutive wet days in the study area. Spatial pattern in the trends of consecutive wet days in the study area is shown in figure $7(\mathrm{~b})$. The figure shows no significant change in consecutive wet days in parts of the study area.

\subsubsection{Dry days}

Maximum consecutive dry and low rainfall days recorded at different stations is averaged to show the changes of consecutive dry days in the study. The graphs of average consecutive dry days and consecutive low rainfall days over the time period 1971-2010 are shown in figure 8(a and b), respectively. Consecutive dry days in the study area is found to decrease at a rate of 2.6 days per decade in last 40 years. On the other hand, consecutive low rainfall days in the study area are found to decrease at a rate of 2.8 days per decade in last 40 years. However, the field significance of the regional trend showed no significant change in any of those indices in the study area. Trends in consecutive dry and low rainfall days in all stations are also computed and interpolated to understand their spatial pattern in the study area. Results show that consecutive dry and low rainfall days have decreased only in a pocket in the upper part of the study area (figure $9 \mathrm{a}$ and $\mathrm{b}$ ).

\subsubsection{Heavy and extreme rainfall days}

Total number of days in a year with rainfall $>20$ $\mathrm{mm}$ (heavy rainfall days) in the study area is shown in figure 10. The figure shows that heavy rainfall days in the study area has increased by 1.5 days per decade over the time period 1971-2010. Field significance of the regional trend of heavy rainfall
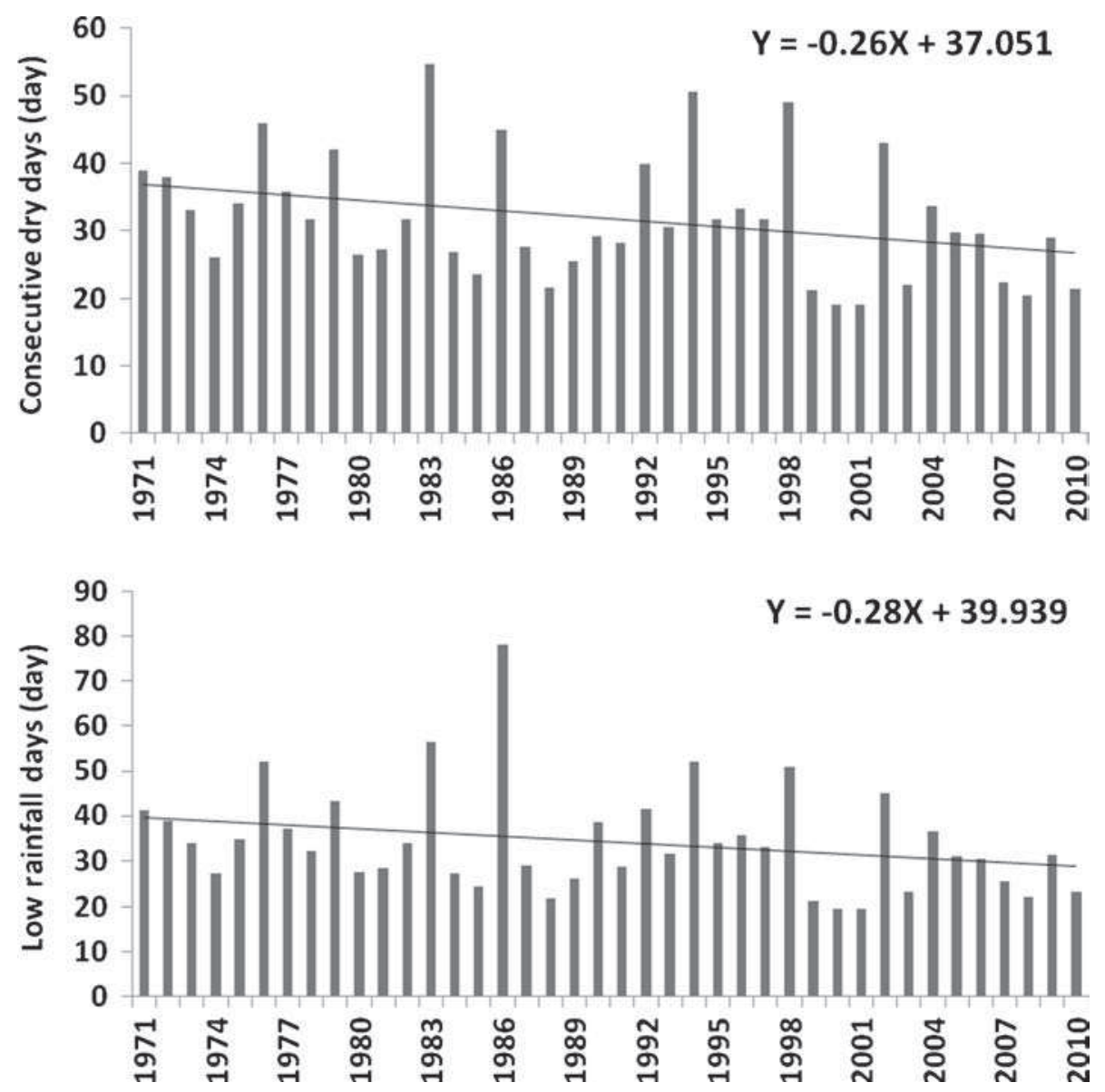

Figure 8. Trends in average (a) consecutive dry days and (b) low rainfall days in the study area over the time period $1971-2010$. 
days (table 3 ) shows that number of heavy rainfall days in the study area has increased significantly at $90 \%$ level of confidence.

Spatial pattern in heavy rainfall days in the study area is shown in figure 11(a). The figure shows that heavy rainfall days in the study area has increased significantly in inland area of the east coast of peninsular Malaysia.

Regional trends in number of days with rainfall more than 95 percentile rainfall over the base period (1971-2000) (extreme rainfall events) show that it is increasing significantly in the study area (table 3). Extreme rainfall events are found to

(a)

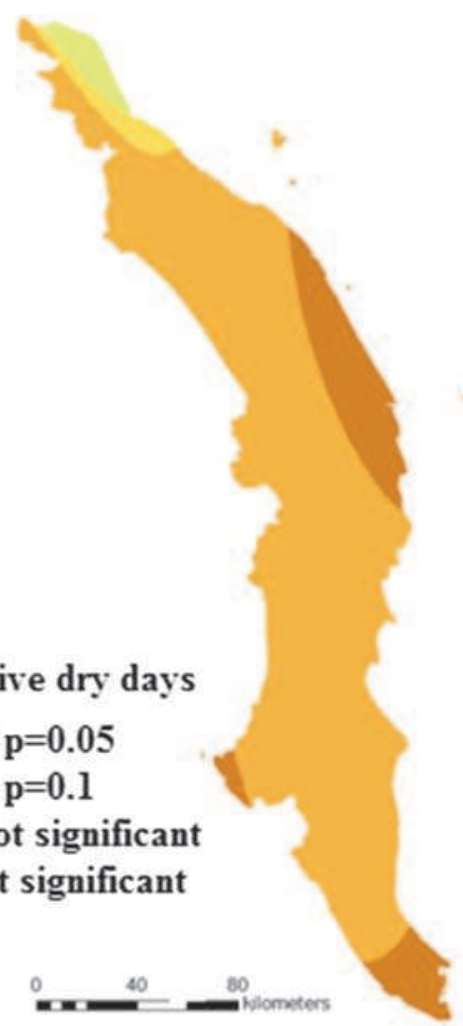

Trend in consecutive dry days

Decreasing at $\mathrm{p}=\mathbf{0 . 0 5}$

Decreasing at $\mathrm{p}=\mathbf{0 . 1}$

Decreasing, not significant

Increasing, not significant increase significantly at 20 out of 54 stations in the region. Spatial pattern in heavy rainfall events in the study area (figure 11b) shows that heavy rainfall in few spots are sporadically distributed over the study area.

\section{Discussion}

The results that have emerged from this study show that rainfall amounts and rainfall-related extremes have increased in the east coast of peninsular Malaysia over the last four decades. In the (b)

\section{Trend in low rainfall days}

Decreasing at $\mathrm{p}=\mathbf{0 . 1}$

Decreasing, not significant

Increasing, not significant
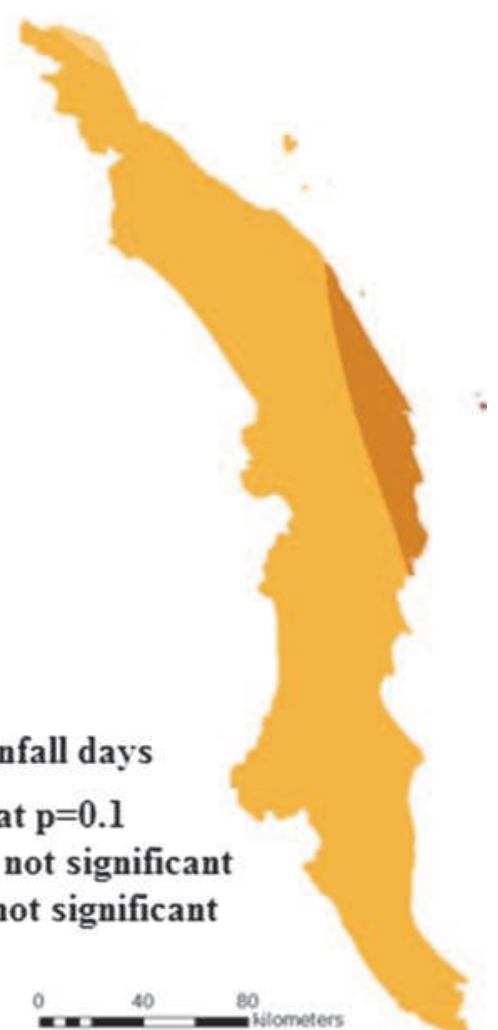

Figure 9. Spatial pattern in (a) consecutive dry days and (b) consecutive low rainfall days.

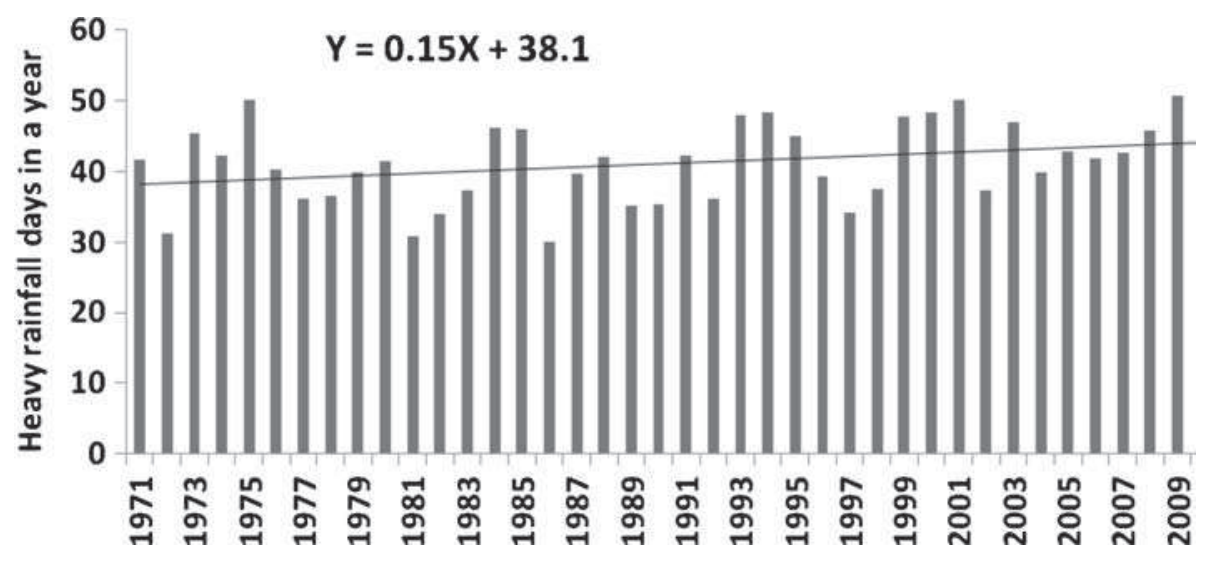

Figure 10. The trends in number of heavy rainfall events in all years. 
case of rainfall total, both the annual and monsoon rainfall have found to show an increase in the study region. The results also show that increased rainfall total is associated with the increase of number of total wet days in a year. However, number of extreme rainfall events like rainfall intensity, consecutive wet or dry days is not found to change significantly in the region. Therefore, it can be remarked that rainfall in the region is now more evenly distributed throughout the years. However, rapid changes in mean annual rainfall can cause changes in the extreme events. The study also reveals that the heavy rain events in the region have increased over the last 40 years. It has been projected by various models that rainfall will continue to increase, which will cause further increase of heavy rainfall events in the east coast of peninsular Malaysia (NAHRIM 2006; Shaaban et al. 2008; MMD 2009). Increased number of heavy rainfall events can increase the frequency of floods in the study area.

The result of the present study is consistent with the climate projected by other researchers using climate models. A number of studies have been carried out by different organizations to project climate in Malaysia (NAHRIM 2006; Wan Azli et al. 2008; MMD 2009; Shaaban et al. 2012). NAHRIM (2006) projected a substantial increase in mean monthly rainfall over the east coastal region. The maximum increase is projected by $11 \%-43 \%$ in upper and lower parts of east coast from the base years (1961-1990) (MMD 2009; Shaaban et al. 2012). High variability in inter-annual and interseasonal rainfalls and river discharge is projected in the area by climate models (NAHRIM 2006; Shaaban et al. 2008, 2012). According to NAHRIM (2006), increasing trends in number of extreme indices such as number of days are with extreme rainfall, number of days with extreme wind, and number of thunderstorm days are found to increase in the region. It has also been projected that there will be significant increase in the overall mean monthly streamflow in the watersheds of east coast and the high flow conditions will be magnified during the wet months (Shaaban et al. 2008). Therefore, the projections indicate more frequent hydrologic extremes such as floods in the east coast of Malaysia.

The future projections of climate by means of Global Climate Models (GCMs) revealed that annual rainfall and few rainfall-related events will continue to increase in the east coast of peninsular Malaysia (NAHRIM 2006). The impact of these changes will be diverse from natural disaster to public health. As the economic activities in most of the southeast Asian countries concentrate in the coastal zones, implication of changing rainfall and extremes will certainly be very severe. Most of the (a)

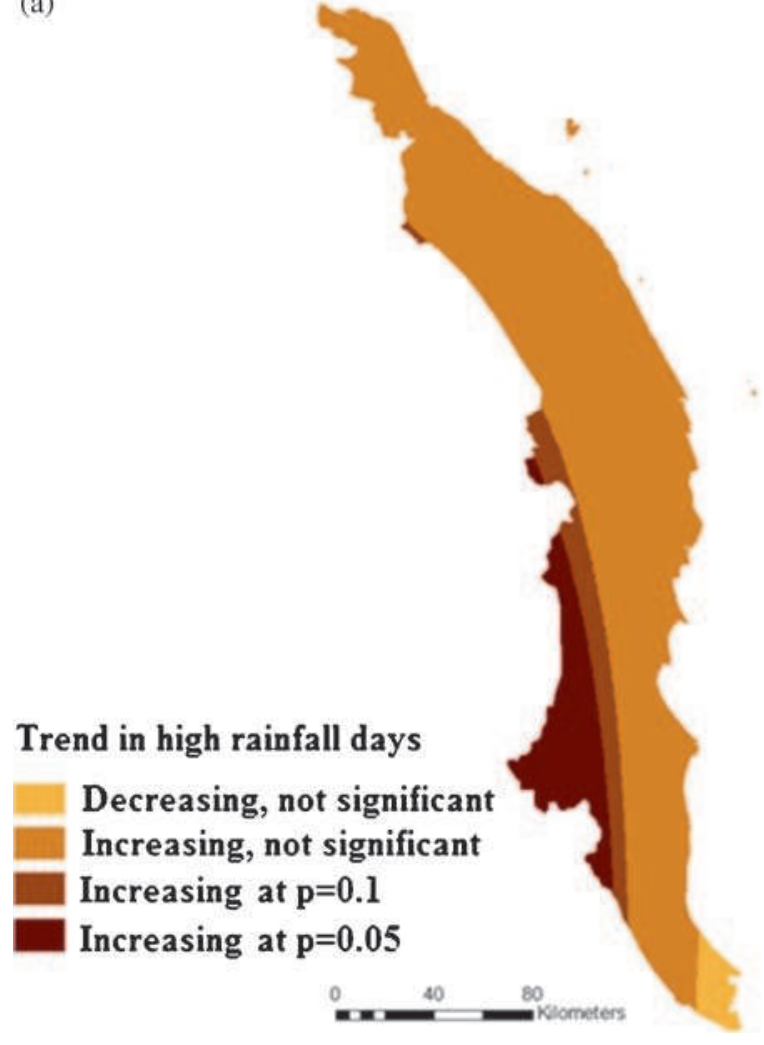

(b)

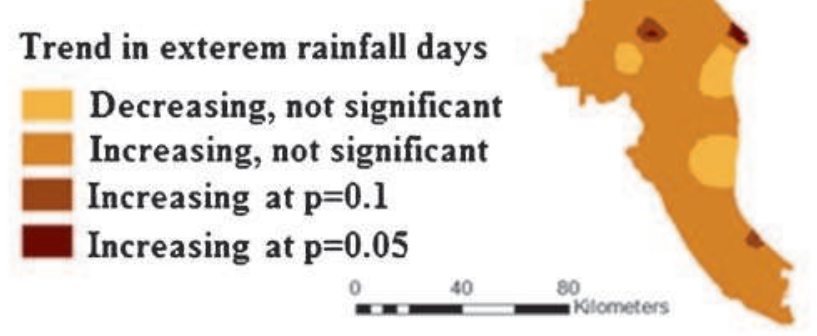

Figure 11. Spatial patterns in (a) heavy rainfall days and (b) extreme rainfall days in all years. 
areas of east coast are low-lying areas that are less than $0.5 \mathrm{~m}$ above the highest tide or are within $100 \mathrm{~m}$ inland of the high-water mark (DID 2011). Therefore, the region is highly vulnerable to sea level rise. National coastal erosion study revealed that about 29\% coastline of Malaysia is facing erosion (DID 2011). Therefore, climate change induced rainfall extremes will certainly aggravate the coastal environment. A study by Shaffril et al. (2011) reported that climate change will reduce the quantity and quality of the sea faunas which will affect productivity in marine resources and expose coastal population to diseases. Begum et al. (2011) and Vaghefi et al. (2011) came to a similar conclusion while assessing climate change impacts in Malaysia.

Increased rainfall and heavy rainfall events may cause congestion in the sewage system. Increased heavy precipitation events may increase the recurrence of flood which is already a major problem in the region. Outbreaks of water-borne diarrhoeal diseases associated with heavy rainfall events are likely to become more frequent in the region. Diseases like cholera and diarrhoea which are positively correlated with the rainfall amount (Shahid 2010b) may also spread with greater intensity. Significant increase of heavy rainfall events and rainfall intensity may trigger more landslides in the region in future. It may also cause more water penetration through exterior walls (Liso et al. 2003) and tend the external building materials (Ahmad 1994) leading to structural damage.

\section{Conclusion}

A study has been carried out in this paper to show the effect of climate variability and changes in rainfall trends in the east coast of peninsular Malaysia. Non-parametric Mann-Kendall test is used to detect the trend and the Sen's slope method is used to determine the magnitude of change in rainfall time series. The Monte Carlo simulation technique is used to determine the significance of the regional trend pattern. Finally, GIS is used to analyze the spatial variation in the trends of rainfall and rainfall-related extremes. Based on the results generated from the analysis of the rainfall data of 54 rainfall stations distributed over the east coast, it can be deduced that the annual and NE monsoon rainfall have increased in the study area over the years. Increase in total number of wet days in a year along with the increase of annual rainfall indicates that rainfall in the region becomes more evenly distributed over the year. Few rainfallrelated extremes like days with rainfall more than $20 \mathrm{~mm}$, days having rainfall more than $95 \%$ over the climatic base period and average rainfall intensity are also found to increase over the east coast of peninsular Malaysia. The economic activities in most of the southeast Asian countries concentrate in the coastal zones. Therefore, implication of these changes will certainly be very diverse and severe in east coast of peninsular Malaysia. It is expected that this study will aid guidance to the understanding of the ongoing changes as well as possible changes in rainfall and rainfall-related extremes in the study area, which in turn will help in adopting necessary adaptation measures to mitigate the negative impacts of climate change in the already stressed east coastal region of peninsular Malaysia.

\section{References}

Ahmad A G 1994. Why Buildings Decay; Paper presented at E\&O Hotel, Penang Heritage Trust, Penang.

Ahmed K, Shahid S and Harun S B 2014 Spatial interpolation of climatic variables in a predominantly arid region with complex topography; Environment Systems and Decisions? 34(4) 555-563.

Alamgir M, Shahid S, Hazarika M K, Nashrrullah S, Harun S B and Shamsudin S 2015 Analysis of meteorological drought pattern during different climatic and cropping seasons in Bangladesh; JAWRA - J. Am. Water Resourc. Assoc., doi: 10.1111/jawr.12276.

Basistha A, Goel N K, Arya D S and Gangwar S K 2007 Spatial pattern of trends in Indian sub-divisional rainfall; Jalvigyan Sameeksha 22 47-57.

Begum R A, Siwar C, Abidin R D Z R Z and Pereira J J 2011 Vulnerability of climate change and hardcore poverty in Malaysia; J. Environ. Sci. Technol. 4(2) 112-117.

Chang H and Kwon W-T 2007 Spatial variations of summer precipitation trends in South Korea, 1973-2005; Environ. Res. Lett. 2045012.

Chu P S and Wang J B 1997 Recent climate change in the tropical western Pacific and Indian Ocean regions as detected by outgoing long wave radiation; J. Climate 10 636-646.

Dempster A, Laird N, Rubin D et al. 1977 Maximum likelihood from incomplete data via the EM algorithm; J. Roy. Stat. Soc. 39(1) 1-38.

Deni S M, Jemain A A and Ibrahim K 2009 Fitting optimum order of Markov chain models for daily rainfall occurrences in peninsular Malaysia; Theor. Appl. Clim. 97 $109-121$.

Deni S M, Suhaila J, Wan Zin W Z and Jemain A A 2010 Spatial trends of dry spells over peninsular Malaysia during monsoon seasons; Theor. Appl. Climatol. 99 357-371.

DID 2011 Coastal Management - Activities, Department of Drainage and Irrigation, Ministry of Natural Resources and Environment, Malaysia. http://www.water.gov. my $/$ index.php?option $=$ com_content\&task $=$ view $\&$ id $=30$ \&Itemid=184/.

Ercan A, Fauzi M, Mohamad B and Kavvas M L 2012 The impact of climate change on sea level rise at peninsular Malaysia and Sabah-Sarawak; Hydrol. Process. 27(3) $367-377$.

Hassan Z, Shamsudin S and Harun S 2013 Application of SDSM and LARS-WG for simulating and downscaling of rainfall and temperature; Theor. Appl. Climatol. 116(1-2) 243-257. 
Isaaks H E and Srivastava R M 1989 An Introduction to Applied Geostatisitics; Oxford University Press, 592p.

Kendall M G 1975 Rank Correlation Measures; Charles Griffin, London, 202p.

Lacombe G, Smakhtin V and Hoanh C T 2013 Wetting tendency in the central Mekong basin consistent with climate change-induced atmospheric disturbances already observed in east Asia; Theor. Appl. Climatol. 111(1-2) 251-263.

Lim J T and Samah A A 2004 Weather and climate of Malaysia, Univ. Malaya Press, Malaysia, 170p.

Lin N, Tsay S, Maring H B, Yen M, Sheu G, Wang S and Liu G 2013 An overview of regional experiments on biomass burning aerosols and related pollutants in southeast Asia: From BASE-ASIA and the Dongsha experiment to 7-SEAS; Atmos. Environ. 78 1-19.

Liso K R, Aandahl G, Eriksen S and Alfsen K H 2003 Preparing for climate change impacts in Norway's built environment; Building Research $\mathscr{G}$ Information 31(3-4) 200-209.

Mann H B 1945 Nonparametric tests against trend; Econometrica 13 245-259.

Manton M J, Haylock M R, Hennessy K J, Nicholls N, Chambers L E, Collins D A et al. 2001 Trends in extreme daily rainfall and temperature in southeast Asia and the south Pacific: 1961-1998; Int. J. Climatol. 21 269-284.

MMD 2009 Report on heavy rain occurrence that cause floods in Kelantan and Terengganu; Gong Kedak Forecast Office, Malaysian Meteorological Department.

NAHRIM 2006 Final report: Study of the impact of climate change on the hydrologic regime and water resources of peninsular Malaysia.

Oki T and Musiake K 1994 Seasonal change of the diurnal cycle of precipitation over Japan and Malaysia; J. Appl. Meteor. 33 1445-1463.

Pour S H, Harun S B and Shahid S 2014 Genetic programming for the downscaling of extreme rainfall events on the east coast of peninsular Malaysia; Atmosphere $\mathbf{5}$ 914-936.

Radziejewski M and Kundzewicz Z W 2004 Detectability of changes in hydrological records; Hydrol. Sci. J. 49(1) 39-51.

Rodrigo F S 2002 Changes in climate variability and seasonal rainfall extremes: A case study from San Fernando (Spain), 1821-2000; Theor. Appl. Climatol. 72 193-207.

Sen P K 1968 Estimates of the regression coefficient based on Kendall's tau; J. Amer. Stat. Assoc. 63 1379-1389.

Serra C, Burgueno A, Martinez M D and Lana X 2006 Trends in dry spells across Catalonia (NE Spain) during the second half of the 20th century; Theor. Appl. Climatol. 85 165-183.

Shaaban A J, Amin M Z M, Chen Z Q and Ohara N 2012 Regional modeling of climate change impact on peninsular Malaysia water resources; J. Hydrol. Eng. 16(12) 1040-1049.

Shaaban J B A, Chen Z Q, Ohara N and Amin M Z M 2008 Regional modeling of climate change impact on peninsular Malaysia water resources; In: Ahupua'A - Proceedings of the World Environmental and Water Resources Congress 2008, 316p.

Shaffril H A M, Samah B A, Uli J and De Silva J L 2011 The potential impact of climate change environmental hazards on quality of life of fishermen community in Malaysia; Austr. J. Basic Appl. Sci. 5(7) 507-515.

Shahid S 2010a Recent trends in the climate of Bangladesh; Clim. Res. 42(3) 185-193.

Shahid S 2010b Probable impacts of climate change on public health in Bangladesh; Asia Pac. J. Public Health 22(3) 310-319.
Shahid S 2011 Trends in extreme rainfall events of Bangladesh; Theor. Appl. Climatol. 104 489-499.

Shahid S and Khairulmaini O S 2009 Spatio-temporal variability of rainfall over Bangladesh during the time period 1969-2003; Asia-Pacific J. Atmos. Sci. 45(3) 375-389.

Shahid S, Harun S B and Katimon A 2012 Changes in diurnal temperature range in Bangladesh during the time period 1961-2008; Atmos. Res. 118 260-270.

Shahid S, Nath S K and Roy J 2000 Ground water potential modelling in a softrock area using GIS; Int. J. Remote Sens. 21(9) 1919-1924.

Shahid S, Wang X-J, Harun S B, Shamsudin S B, Ismail $\mathrm{T}$ and Minhans A 2015 Climate variability and changes in the major cities of Bangladesh: Observations, possible impacts and adaptation; Regional Environmental Change, doi: 10.1007/s10113-015-0757-6.

Sneyers R 1990 On the statistical analysis of series of observation; WMO, Technical Note No. 143, Geneva, Switzerland.

Su B D, Jiang T and Jin W B 2006 Recent trends in observed temperature and precipitation extremes in the Yangtze River basin, China; Theor. Appl. Climatol. 83 139-151.

Suhaila J and Jemain A A 2007 Fitting the statistical distributions to the daily rainfall amount in peninsular Malaysia; J. Teknologi 46C 33-48.

Suhaila J and Jemain A A 2009 Investigating the impacts of adjoining wet days on the distribution of daily rainfall amounts in peninsular Malaysia; J. Hydrol. 368(1-4) $17-25$.

Suhaila J, Deni S M and Jemain A A 2008 Detecting inhomogeneity of rainfall series in peninsular Malaysia; Asia-Pacific J. Atmos. Sci. 44 369-380.

Suhaila J, Deni S M, Wan Zin W Z and Jemain A A 2010 Trends in peninsular Malaysia rainfall data during the southwest monsoon and northeast monsoon seasons: 1975-2004; Sains Malaysiana 39(4) 533-542.

Tangang F T, Juneng L, Salimun E, Sei K M, Le L J and Muhamad H 2012 Climate change and variability over Malaysia: Gaps in science and research information; Sains Malaysiana 41(11) 1355-1366.

Toriman M E, Pereira J J, Gasim M B, Sharifah Mastura S A and Aziz N A A 2009 Issues of climate change and water resources in peninsular Malaysia: The case of north Kedah; Arab World Geographer 12(1-2) 87-94.

Vaghefi N, Nasir Shamsudin M, Makmom A and Bagheri M 2011 The economic impacts of climate change on the rice production in Malaysia; Int. J. Agri. Res. 6(1) 67-74.

van Beers W C M and Kleijnen J P C 2004 Kriging interpolation in simulation; In: A Survey Proc. 2004 Winter Simulation Conference, Washington (eds) Ingalls R G, M D Rossetti, J S Smith and B A Peters, pp. 113-121.

Wan Azli W H S, Mohan K and Kumarenthiran S 2008 Climate change scenario and the impact of global warming on the winter monsoon; In: Second National Conference on Extreme Weather and Climate Change: Understanding Science and Risk Reduction, 14-15 October 2008, Putrajaya, Malyasia.

Wang X-J, Zhang J-Y, Shahid S, Guan E-H, Wu Y-X, Gao J and He R-M 2014 Adaptation to climate change impacts on water demand; Mitigation and Adaptation Strategies for Global Change, doi: 10.1007/s11027-014-9571-6.

Wong C L, Venneker R, Uhlenbrook S, Jamil A B M and Zhou Y 2009 Variability of rainfall in peninsular Malaysia; Hydrol. Earth Syst. 6 5471-5503.

You Q, Kang S, Aguilar E and Yan Y 2008 Changes in daily climate extremes in the eastern and central Tibetan 31 plateau during 1961-2005; J. Geophys. Res., doi: 10.1029/2007JD009389. 
Yue S and Hashino M 2003 Long term trends of annual and monthly precipitation in Japan; J. Am. Water Resour. Assoc. 39(3) 587-596.

Yue S, Pilon P and Cavadias G 2002 Power of the MannKendall and Spearman's Rho tests for detecting monotonic trends in hydrologic series; J. Hydrol. 259(1-4) $254-271$.

Yusuf A A and Francisco H A 2009 Climate change vulnerability mapping for southeast Asia; Economy and
Environment Program for Southeast Asia (EEPSEA), http://web.idrc.ca/uploads/userS/12324196651MappingReport.pdf.

Zawiah W, Zin W and Jamaludin S 2010 Recent changes in extreme rainfall events in peninsular Malaysia: 19712005; Theor. Appl. Clim. 99 303-314.

Zhang X, Zwiers F W and Li G 2004 Monte Carlo experiments on the detection of trends in extreme values; J. Climate 17 1945-1952. 